\title{
A Model to Develop Peer Feedback Skills in First-Year ENGINEERING STUDENTS
}

\author{
Stephen Mattucci, Jim Sibley, Jonathan Nakane and Peter Ostafichuk \\ University of British Columbia \\ ostafichuk@mech.ubc.ca
}

\begin{abstract}
Giving and receiving feedback is a necessary, but often difficult skill for young engineers to acquire. We developed and piloted the delivery of a feedback model as part of the first-year engineering experience at the University of British Columbia. The approach is based on recognizing feedback as a form of professional communication, and that it requires practice to improve. We wove different aspects of communication skill development through two large newly-designed first-year introduction to engineering courses, building towards face-to-face feedback through a staged series of communication experiences.

The full feedback model highlighted the nuances of faceto-face communication, and was called the " $3 \times 3$ ", since it includes the three components involved in face-to-face feedback (sender, message, and receiver), each with three associated aspects. The sender uses appropriate words and body language, ensures proper interpretation, and is empathetic; the message is objective and non-judgmental, sufficiently detailed, and contains suggestions for improvement; and the receiver remains open and listening, acknowledges to the sender that they are listening, and clarifies to ensure understanding.

Students applied what they had learned through an activity reviewing poster presentations from a major course design project. In the activity, they each had an opportunity to craft a feedback message before delivering the message face-to-face to a peer. Students then reflected on the feedback they received by summarizing the message, recognizing how the sender delivered the feedback, and identifying why the feedback was helpful. Student reflections were analyzed for themes from the $3 \times 3$ model.

Students found feedback from peers particularly helpful when it was delivered in an appropriate and courteous manner, checked for proper interpretation, provided clear suggestions for improvement, and was coupled with praise of something that was done well.

Providing students with a structured model allows them to follow a process in both providing effective face-to-face feedback, but also better appreciate why receiving feedback is beneficial in helping them improve.
\end{abstract}

\section{INTRODUCTION}

The development of effective communication skills is essential for engineering students to achieve success in their future careers [13]. This not only involves learning to successfully write and verbally communicate, but also build on these skills to address complexities and nuances that exist in a face-to-face interaction. Particularly, learning how to give and receive one-on-one feedback is one of the core communication skills students need to develop. However this can be intricate when coupled with principles of formative feedback, which can cause students to feel vulnerable.

Historically, activities involving giving and receiving feedback can be difficult and uncomfortable tasks for students, often met with a lack of full student participation [11]. A learning-focused strategy, modeling appropriate feedback techniques [11], and employing qualitative feedback over numeric evaluations [8], may be beneficial for students to understand the value of the peer feedback process, and motivate student engagement. To help students develop this important aspect of communication, we developed the " $3 \times 3$ feedback model" and piloted a progression of communication activities as part of the firstyear engineering experience at the University of British Columbia (UBC). The communication skill development activities were embedded throughout a redesigned twocourse, first-year introduction to engineering sequence. The activity sequence touched on multiple forms of professional communication; one core activity was a faceto-face feedback opportunity for students, where they got to practice both giving and receiving feedback using the newly-developed $3 \times 3$ model, then reflected on their experiences.

Our objective was to develop a concise peer-to-peer feedback structure which encompasses the three components of a feedback interaction (sender, message, and receiver). The model synthesizes elements from multiple communication guidelines, to provide first-year engineering students a framework to practice and develop interpersonal skills. Through use of this model, we also sought to determine the specific feedback elements students found most useful when receiving feedback based on reflection responses.

CEEA17; Paper 096

University of Toronto; June 4 - 7, $2017 \quad-1$ of 7 - 


\section{COURSE CONTEXT}

Two new introduction to engineering courses were launched at UBC in 2015 [9]. The courses are taught in a flipped-classroom format, with a sequence of online, largeclass, and studio components arranged in a whole-partwhole structure. The courses rely heavily on elements of Team-Based Learning [12], and are supported by an array of online tools and digital resources.

Both courses are 13 weeks in length and have 4 contact hours per week. APSC 100 is comprised of four modules: 1) introduction to design, 2) introduction to decisionmaking, 3) CAD and rapid prototyping, and 4) ethics and professional practice. APSC 101 is comprised of three modules, numbered in continuation from APSC 100: 5) technical skills in design, 6) sustainability, and 7) cornerstone design. The cohort is divided into 4 large class sections in each course (roughly 200 students each) and 1315 design studio sections (roughly 60 students each). Each week, following mandatory online preparation, each student has two 50-minute classes that bookend a single 110-minute design studio class.

The sequence of communication activities was embedded in the seven module sequence spanning two consecutive courses (Fig. 1). The first module of APSC 100 introduced the course and the design process, and featured a small design project. It did not include instruction in any feedback- or communication-related content; however, at the end of the module, there was a design showcase where students outlined their design process via posters. Shortly after the conclusion of the module, there was a peer evaluation activity, completed using iPeer (an online platform for peer feedback between team members). In the second course module, we introduced the notion of pre-communication analysis of audience, purpose, and context ("A-P-C" in Fig. 1). This was linked to the preparation of a formal oral presentation at the end of that module, and, again, there was a peer evaluation event on iPeer. In the third course module, we focused on crafting a clear message; for this, we introduced three elements of the $7 \mathrm{C}$ framework: clear, concise, and correct [2]. Students applied this framework as they prepared both a technical memorandum and an elevator pitch. The focus of the fourth and final course module of the first term was on professionalism and ethics. We introduced the remaining 7 Cs (concrete, coherent, complete, and courteous) as they related to professional written feedback. The focus was on crafting an effective feedback message, which represented one-third of the $3 \times 3$ framework. Students applied the analysis of audiencepurpose-context, the $7 \mathrm{C}$ framework, and partial consideration of the $3 \times 3$ framework to craft written feedback for peers, explicitly linked to the need for engineers to give "fair and honest professional comment."[1] Students practiced crafting a clear feedback message while completing an anonymous, online peer assessment exercise based on the technical memorandum from Module 3. This was facilitated using the peerScholar ${ }^{\mathrm{TM}}$ online peer review tool for both submission and review [10]. In addition, we discussed the application of the principles of feedback to peer evaluations.

Next, in the first module of APSC 101 (Module 5) we introduced our full $3 \times 3$ feedback model, highlighting the nuances and difficulties of face-to-face communication, and including elements of the Situation-Behaviour-Impact (SBI) model for feedback [6]. Students practiced using this feedback model when giving and receiving feedback at the final course poster showcase (the dark dot in Fig. 1). In some respects, this was the culminating peer assessment event in the courses since it required considerations of the full $3 \times 3$ model. Students prepared by first reviewing multiple posters from other teams and writing a summary of a key piece of feedback on a sticky note. They then delivered the message face-to-face to another student at the poster, placing the sticky note on the poster as a record for the receiver of the feedback. Each student had multiple opportunities to both give and receive feedback. Students reflected on their feedback interactions, and the responses were analyzed to determine which elements of the feedback model used lead to the most effective feedback.

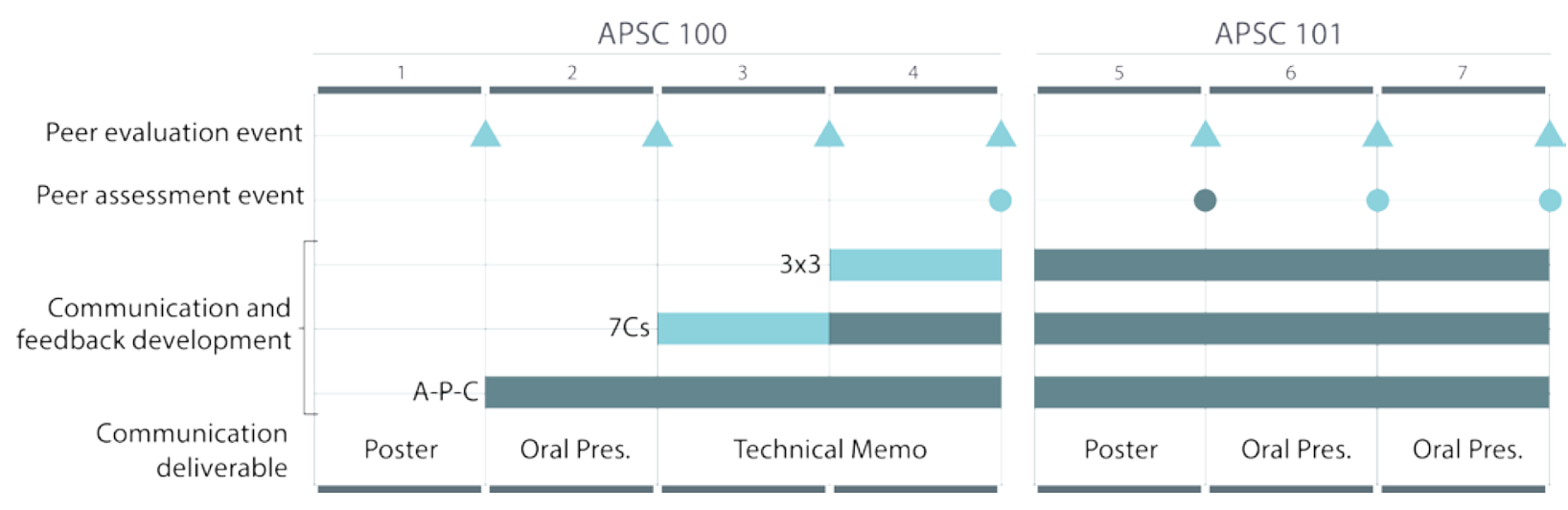

Fig. 1 Progression of Course Deliverables. Three of the 7 Cs were introduced in Module 3, and continued in Module 4, while Message was introduced from the $3 \times 3$ in Module 4 and Sender and Receiver added in Module 5.

CEEA17; Paper 096

University of Toronto; June 4- 7, $2017 \quad-2$ of 7 - 
Although not discussed further in this paper, feedback opportunities continued in the course with the peer assessment of a business letter and expression of interest for a remote water treatment project in Module 6, and for a formal oral presentation on a design project in Module 7. In addition, feedback was given through required iPeer evaluations at the end of each module, but teams were also encouraged to continue using the principles of the $3 \times 3$ model for face-to-face feedback within their teams.

\section{THE $3 \times 3$ FEEDBACK MODEL}

In trying to give students a simple yet useful framework for giving and receiving feedback, we developed a model to outline important aspects of a feedback interaction. An overview of the model, a description of its origins, and descriptions of how it is implemented and applied in the courses are outlined below

\subsection{Overview of $3 \times 3$ Model}

We dubbed our feedback model the " $3 \times 3$ " since it includes the three interacting components involved in faceto-face feedback (sender, receiver, and message), each with three key points to consider. The elements of the $3 \times 3$ are depicted in Fig. 2.

\begin{tabular}{|l|l|}
\hline \multicolumn{1}{|c|}{ Sender } \\
\hline $\begin{array}{l}\text { Use appropriate words, tone, and body } \\
\text { language }\end{array}$ \\
\hline $\begin{array}{l}\text { Check for understanding to ensure proper } \\
\text { interpretation }\end{array}$ \\
\hline Observe the receiver and be empathetic \\
\hline Message \\
\hline Objective and non-judgemental \\
\hline Provide sufficient detail \\
\hline Make clear suggestions for improvement \\
\hline
\end{tabular}

\begin{tabular}{|l|}
\hline \multicolumn{2}{|l|}{ Receiver } \\
\hline Remain open and listening \\
\hline $\begin{array}{l}\text { Acknowledge that you have heard and are } \\
\text { listening }\end{array}$ \\
\hline Clarify or paraphrase to ensure understanding \\
\hline
\end{tabular}

Fig. 2. 3×3 Feedback Model

Sender: Since the model focuses on interpersonal interactions, the sender must go further than simply delivering a message and ensure that the message is properly received. Even if the message is clear and wellcrafted, if the receiver is not ready for the feedback or not engaged, the message may not have any effect. To achieve this, the sender must use appropriate words, body language, and tone; ensure proper interpretation of the message; and observe the receiver and be empathetic.

Message: The message should be clear and concise enough to stand by itself. Even though face-to-face communication has the luxury of clarification of meaning, a message will have the greatest impact if it is not confusing or requiring of interpretation. The message must be objective and non-judgmental; sufficiently detailed to explain the impact of the issue or error; and contain clear suggestions for improvement.

Receiver: The typical immediate reaction of people receiving feedback is to act defensively, often coming up with counterarguments or explanations, rather than simply listening. Effectively listening can be difficult for people who are not familiar with receiving feedback, but this becomes easier with practice. The receiver must strive to remain open and listening; acknowledges to the sender that they are listening; and clarify or paraphrase to ensure understanding.

\subsection{Genesis of the $3 \times 3$ Feedback Model}

Many different communication feedback models exist that can be applied to many different kinds of communication situations, however none of the ones reviewed by the team were directly applicable to a face-toface feedback situation, and we felt that there were too many nuances for students to simply remember a list of guidelines. The $3 \times 3$ Model grew as a combination of these models, directly applicable to face-to-face feedback, synthesized into one model to help students adequately structure their interactions. Michaelsen and Schultheiss's Making Feedback Helpful outlines 7 important considerations to make feedback most helpful [4]. The 7 Cs framework focuses primarily on creating clear message, but does contain a few elements relating to delivery, like courteousness [5]. The Situation-Behaviour-Impact (SBI) model focuses comments on specific situations and behaviours, and then outlines the impact of those behaviours on others [6].

The $3 \times 3$ model contains components that are found in many of these and other models, but what is unique about the $3 \times 3$ is the intentional division into three elements: sender, message, and receiver. We felt it necessary to make these explicit categories to draw student attention to these three important interacting aspects of interpersonal communication in a face-to-face feedback situation. The $3 \times 3$ model progresses from a one-way interaction (e.g. 
written message), to the addition of the face-to-face dynamic, to a deeper model with multiple communication pathways including verbal and non-verbal, where the message needs to be delivered and ensured it was received properly by observing the receiver, who is also communicating back to the sender (Fig. 3).
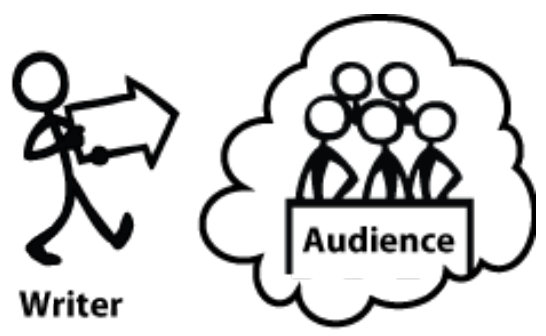

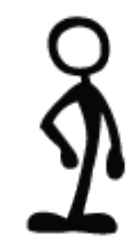

Sender

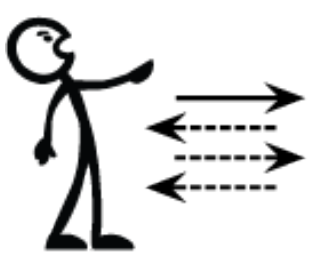

Sender

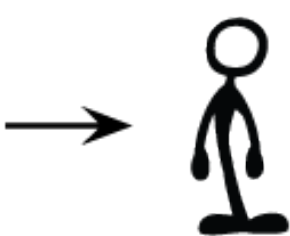

Receiver

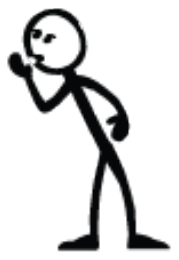

Receiver
Fig. 3. Progression of communication, from simple oneway communication, to delivering a message face-to-face,

to interactions with multiple communication pathways involving non-verbal cues, and observations from both the sender and receiver.

\subsection{Implementation within the course}

The $3 \times 3$ feedback model was introduced to the students by means of an interactive online video. The video builds on the communication themes already introduced in the courses, mainly the idea of the importance of Audience, Context, and Purpose, regardless of whether preparing for written or verbal communication. The video focused on face-to-face verbal communication in the context of giving and receiving feedback. A core message of the video is that giving and receiving feedback takes practice, so as not to discourage the students who may initially feel uncomfortable with these types of interactions.

The first section of the video introduces three different types of feedback: appreciation, coaching and evaluation, and the underlying purpose for each [15]. Appreciation feedback acknowledges, thanks, or gives credit to someone; Evaluation feedback scores a performance against expectations; and Coaching feedback is intended to help someone improve. We decided to focus student attention on Coaching feedback, as this kind of feedback can be difficult for students to receive, despite the positive underlying intentions. The video concludes by revisiting the 7 Cs framework, previously introduced in class. All 7 Cs apply to the message, but Clear, Concise and Courteous were emphasized as being particularly applicable to faceto-face feedback.

Students first tried using the $3 \times 3$ Feedback Model during large class activities, with an interactive roleplaying activity where students practiced with each other using fictitious scenarios and feedback prompts. Students practiced delivering and receiving feedback and considered how it feels being on each side of a feedback message. Students paired up with members from other teams to add authenticity. Students were prompted to observe and reflect during the experience. Specifically, as the sender, students watched the body language of the receiver and adjusted the delivery if needed to ensure the message was heard. As the receiver, students watched for when they felt vulnerable, and when they might have needed to resist instinctive feelings of defensiveness that might impact their ability to listen.

\subsection{Application of the feedback model}

The module concluded with a project design competition and poster session within each two-hour studio session, which involved approximately ten teams, and 60 students. The first hour was dedicated to the design competition, followed by a poster presentation showcase. The logistics to execute the same procedure effectively for each of the thirteen studio sessions required a clear schedule detailing where each team needed to be at all times. The poster session included a 36-minute "feedbackfree-for-all," where each team had two members present at their own poster while other members circulated the room providing face-to-face feedback to other teams. During the session, members swapped between roles. To provide feedback, students consulted a poster and carefully crafted their message according to the $3 \times 3$ model, writing comments on a small sticky note. When ready, the student would consult a member of the poster team, and verbally provide the feedback face-to-face. The sender would then place the note on the relevant area of the poster. It was emphasized that the note was meant as a reference to the feedback, not a replacement of the feedback. Each student was given two sticky notes so each poster would receive approximately twelve pieces of feedback (teams were comprised of 6 students on average). Students were aware they would be submitting a reflection on their experience as a receiver of feedback so they could be conscious of their feelings during the interaction. 
Following the feedback round, teams reflected on all of the feedback they had received, and ranked the received feedback from most to least useful. For the two most useful pieces of feedback, the members of the team who received those messages commented on the following:

i. A summary of the feedback messages received in their own words.

ii. Why the feedback was helpful, and specifically how it could help improve their future work.

iii. Some specific actions of the sender during delivery that made the feedback more effective.

To motivate students to provide useful feedback to their peers, the class was notified that the two most useful feedback messages identified by a receiving team would earn bonus marks for the sender's team. Students are more likely to provide detailed feedback if they know the feedback will be well received or if incentives are involved [7].

\subsection{Analysis of student responses}

Each team submitted responses for the two most useful pieces of feedback they received, using an online survey. There were a total of 261 responses each to questions ii and iii from Section 3.4. The responses were primarily analyzed for mention of one or more of the components of the $3 \times 3$ model, or use of one or more of the $7 \mathrm{Cs}$. Comments that made no reference to the specific feedback elements were either non-descriptive, or specific to the project, for example: "this feedback was helpful as it would have enabled us to make the perfect poster." Other emerging themes from the responses were also qualitatively noted.

\section{RESULTS AND DISCUSSION}

\subsection{Observations of feedback event}

From independent anecdotal observations of three of the authors, we estimated that approximately 35\% of student participants were fully engaged in the face-to-face feedback process (making an honest effort to give and receive constructive feedback according to the $3 \times 3$ model), $40 \%$ were partially engaged and at least went through the motions expected, and $25 \%$ were visibly not engaged. We independently asked studio instructors and teaching assistants for their perception of the proportions of students belonging in each of the three groups, and those four responses averaged 50\% fully engaged, $30 \%$ partially engaged, and $20 \%$ disengaged. Taken together, this suggests that a significant proportion of the class-over three-quarters-were willing to engage in the face-to-face feedback activity.

CEEA17; Paper 096

University of Toronto; June 4 - 7, $2017 \quad-5$ of 7 -

\subsection{Analysis of feedback reflections}

The percentages of responses that addressed each element are presented in Table 1. Clear themes emerged that were parallel in the responses to both questions. Interestingly, many responses mentioned how feedback was helpful when it was coupled with praise or a compliment of something the team did well. This was then added to the criteria for analyzing responses. For example: "Leading with a compliment improved receptiveness to ideas for improvement.” Almost one-third of responses mentioned this was something the sender did to make the constructive feedback more effective. Given this perceived effectiveness, it may be worth including in future adaptations of feedback lessons.

Table 1: Percentage of student feedback reflections containing elements from the $3 \times 3$ feedback model.

\begin{tabular}{|c|c|c|}
\hline $\begin{array}{l}\text { ii. Why was the } \\
\text { feedback helpful? }\end{array}$ & \multicolumn{2}{|c|}{$\begin{array}{c}\text { iii. What the sender did to } \\
\text { make the feedback } \\
\text { effective }\end{array}$} \\
\hline \multicolumn{3}{|c|}{ Sender } \\
\hline & Words, tone, body language & $35 \%$ \\
\hline & Check understanding & $22 \%$ \\
\hline & Observe and be empathetic & $18 \%$ \\
\hline \multicolumn{3}{|c|}{ Message } \\
\hline $5 \%$ & Objective observations & $17 \%$ \\
\hline $15 \%$ & Specific details & $21 \%$ \\
\hline $21 \%$ & Suggestions to improve & $25 \%$ \\
\hline \multicolumn{3}{|c|}{ 7Cs } \\
\hline $4 \%$ & Clear & $38 \%$ \\
\hline $2 \%$ & Concise & $15 \%$ \\
\hline $2 \%$ & Courteous & $31 \%$ \\
\hline $2 \%$ & $\begin{array}{c}\text { Concrete, Correct, } \\
\text { Coherent, or Complete }\end{array}$ & $14 \%$ \\
\hline $9 \%$ & Praise or compliment & $29 \%$ \\
\hline $40 \%$ & Non Descriptive & $3 \%$ \\
\hline $21 \%$ & Project specific & $2 \%$ \\
\hline \multicolumn{3}{|c|}{ Total responses: 261} \\
\hline
\end{tabular}

The number of responses not specifically related to the feedback was concerning for question ii. However, we believe this is mostly related to the wording of the question, and the circumstance. Students had just completed a design competition and poster presentation following five intensive weeks of preparation, so were naturally in the mindset of how they could have improved related to the course objectives. Responses were mostly focused around what they could have done differently to achieve an 
improved competition or poster outcome, rather than identify specific technical communication elements of the feedback message that were helpful. This was elucidated in question iii, when specifically prompted to reflect on aspects of the feedback process, as only $5 \%$ of responses were not related to the feedback.

With respect to the feedback message, at least $21 \%$ of students identified suggestions of how to improve as most useful in response to both questions. Helping students to understand what an improved version might look like may help them to understand their own shortcomings. Related to the sender, $35 \%$ of students found the delivery (words, tone and body language) to be a very important contributor towards effective feedback, and $22 \%$ found it helpful when the sender verified their understanding. The usefulness of these two elements emphasizes the importance of face-toface feedback communication, as the intent of the sender may be misinterpreted if writing is the sole medium, and further meaning can be conveyed non-verbally. In response to both questions, students found clear, courteous and concise, each more useful than the other four combined. These were the three Cs emphasized as most relevant to the sender and receiver, and additionally, clear and concise were two of the first three Cs introduced earlier in the course. It is apparent that courteousness became an important element to the students when the face-to-face dynamic was added to the interaction.

\subsection{Lessons Learned}

Communication skills are very important for engineers to learn, however can be challenging to address in the classroom in an authentic manner, as others have reported limited engagement [11]. The development of the structured $3 \times 3$ model allowed for some targeted insight towards the student learning process of a successful feedback interaction, as well as some continued challenges for meaningful student learning, leaving opportunities for continued improvements in future iterations.

After developing an online screencast video to introduce feedback communication, it was difficult to generate interactive questions that were relevant to the students and of appropriate difficulty. Feedback is very situation dependent, and capturing a specific context can be challenging.

It was difficult to motivate adequate buy-in during the in class activity that led up to the poster showcase. Feedback is a difficult subject, and can be awkward or uncomfortable for students attempting to role play scenarios, especially in large classrooms. We would recommend focusing on the perceived value, and have feedback lessons build up to obvious applications relevant to the students.

The progression of communication models throughout the course worked well. By allowing communication elements to be slowly added and built upon students were never overwhelmed by abstract communication concepts and had opportunities to incrementally implement these concepts at early stages before being expanded upon.

Proper organization of the space during the poster session was critical, so as to be conducive of meaningful interactions. Changes were implemented after the first poster session with noticeable improvements in student engagement. Namely, posters were spaced apart to avoid crowding, and chairs were removed to discourage students from sitting and being closed-off to peer interactions.

Incorporating an assessment component of a face-toface feedback interaction, without interfering with the interaction, was difficult. The sticky notes allowed students to reference the feedback interactions afterwards. However, despite emphasizing the sticky notes as means to support the feedback, many students were observed delivering written notes to their peers, avoiding the faceto-face interaction. We realized after the showcase that having the sender write the feedback enabled this avoidance, and we recommend instead to have the receiver take written notes while receiving feedback. This method would also naturally encourage clarification of the feedback message to ensure proper interpretation, giving students a greater appreciation of the difficulty of clearly communicating concepts.

Several feedback reflection responses mentioned the usefulness of a different perspective. This is a fundamental concept with respect to the value of feedback, and could have been emphasized further when introducing the motivation behind developing this skill. Several comments also mentioned awareness of the potential of the sender to upset the receiver, and the importance of being empathetic, demonstrating that first-hand practice of these skills strengthens understanding.

Our findings of student feedback giving direct recommendations and highlighting what was done correctly mirrors findings from a previous study analyzing the quality of student peer-peer written feedback [3]. However, these previous findings mentioned a primarily negative undertone to the feedback which discouraged the receiver. Emphasizing the roles using the $3 \times 3$ model, and allowing students to experience both sides of giving and receiving feedback may have provided students a deeper understanding of why they found feedback helpful, and applied these same techniques while delivering feedback.

\section{CONCLUSIONS}

Our goal has been to teach students that it is not only important to craft a clear and meaningful feedback message, but to also focus on how the message is delivered, and how it is received. We highlighted to students that giving and receiving feedback can be a difficult and lifelong process to develop and improve, especially face-toface, and they must be actively engaged during this 
Proc. 2017 Canadian Engineering Education Association (CEEA17) Conf.

process. Providing students with a structured model allows them to follow a process in both providing effective faceto-face feedback, but also better interpret received feedback and appreciate why receiving feedback is beneficial in helping them improve.

Responses from our class exercise suggest students find feedback most helpful when it is courteously delivered with appropriate tone and body language, checked for proper understanding, includes clear suggestions for improvement, and includes praise for things done well.

\section{Acknowledgements}

We wish to thank the University of British Columbia Teaching and Learning Enhancement Fund (TLEF) for funding the work to redevelop our first year engineering curriculum.

\section{References}

[1] For example, APEGBC Code of Ethics, [Online]. Accessed: https://www.apeg.bc.ca/getmedia/e8d858f5e175-4536-8834-34a383671c13/APEGBC-Code-ofEthics.pdf.aspx

[2] S. Cutlip, and A. Center, Effective Public Relations: Pathways to Public Favor. Prentice-Hall, 1952.

[3] F. Marbouti, H.A. Diefes-Dux, and M.E. Cardella, "Students' and engineering educators' feedback on design." in American Society for Engineering Education Annual Conference, ASEE15, 10 pp, Seattle, WA 2015.

[4] L. Michaelsen and E. Schultheiss, "Making Feedback Helpful,” Organizational Behavior Teaching Review, Vol 13, No. 1, pp. 109-13, 1988.

[5] Mindtools, The 7 Cs of Communication: A checklist for clear communication, [Online]. Available:

https://www.mindtools.com/pages/article/newCS_85.htm

[6] Mindtools, The Situation-Behavior-Impact Tool, [Online]. Accessed:

https://www.mindtools.com/pages/article/situationbehavior-impact-feedback.htm
[7] G. Neubaum, A. Wichmann, S.C. Eimler, and N.C. Krämer, "Investigating incentives for students to provide peer feedback in a semi-open online course: An experimental study," in Proc. of The International Symposium on Open Collaboration, 19 pp., Berlin, Germany, 2014.

[8] L.M. O'Moore, and T.E. Baldock, "Peer assessment learning sessions (PALS): an innovative feedback technique for large engineering classes,” European Journal of Engineering Education, 32, pp. 43-55, 2007.

[9] P.M. Ostafichuk, C.P. Jaeger, J. Nakane, S. Nesbit, N. Ellis, and J. Sibley, "Redesigning the UBC First Year Introduction to Engineering: Successes and Challenges," in Proc. of CEEA 2016, 8 pp., Halifax, 2016.

[10] D. Paré and S. Joordens, "Peering into large lectures: examining peer and expert mark agreement using peerScholar, an online peer assessment tool,” Journal of Computer Assisted Learning, Vol. 24, No. 6, pp. 526-40, 2008.

[11] K.J. Rodgers, H.A. Diefes-Dux, and M.E. Cardella, “The nature of peer feedback from first-year engineering students on open-ended mathematical modeling problems." In American Society for Engineering Education Annual Conference, ASEE12, 23 pp, San Antonio, TX, 2012.

[12] J.E. Sibley, and P.M. Ostafichuk, Getting Started with Team-Based Learning. Sterling, Virginia: Stylus, 2014, 256 pp. \{ISBN: 978-1620361962\}

[13] C. M. Spretnak, “A Survey of the Frequency and Importance of Technical Communication in an Engineering Career,” Technical Writing Teacher, Vol. 9, No. 3, pp. 1336, Spr, 1982.

[14] D. Stone, and S. Heen, Thanks for the Feedback. Viking, 2014

[15] S.R. Weitzel, Feedback that works: How to build and deliver your message, Pfeiffer, 2011. 